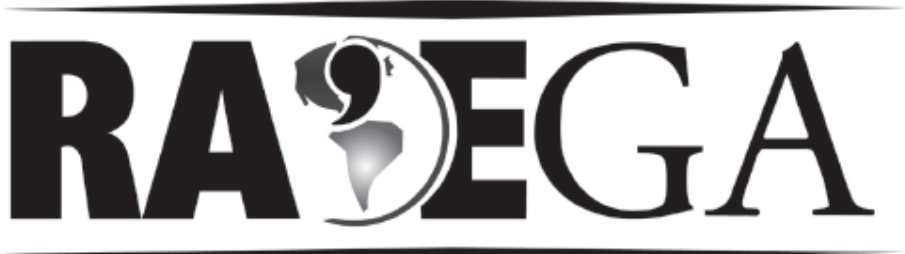

O ESPAÇO GEOGRÁFICO EM ANÁLISE

\title{
TURISMO, TRANSPORTES E REGIONALIZAÇÃO: CONSIDERAÇOES GEOGRÁFICAS
}

\section{TOURISM, TRANSPORT AND REGIONALISATION: GEOGRAPHICAL CONSIDERATIONS}

\author{
Wilson Martins Lopes Júnior ${ }^{1}$
}

\section{RESUMO}

Esse artigo se propõe a colaborar na importante discussão sobre regionalização com ênfase no turismo e nos transportes, refletindo sobre 0 desenvolvimento regional. Realizou-se uma discussão sobre região (regionalização), conceito cerne da geografia de modo a explicitar e reconhecer o tema transportes e turismo como objetos da ciência geográfica diante de suas interferências no território e reflexos no espaço geográfico. Destacou-se também a importante relação entre o turismo e o espaço geográfico na qual o turismo consome o espaço e os seus elementos de modo a imprimir mudanças no território, como do uso e da instalação de equipamentos públicos. A importância dessa discussão está em contribuir para pesquisas desde a clássica geografia regional até a geografia dos transportes e geografia do turismo. Pesquisas sobre esta temática são importantes ao poder público nos diferentes níveis de planejamento para implementar as políticas públicas regionais.

Palavras chaves: regionalização; turismo; transportes; geografia do turismo; regionalização do turismo.

\footnotetext{
1 Doutor em Geografia, Professor Adjunto do Departamento de Geografia de Campos (GRC) da Universidade Federal Fluminense (UFF), Pesquisador dos grupos: "GEOETUR - Geografia, Espaço e Turismo" (UFF) e "Turismo, Território e Cultura" (UECE). Campos, Rio de Janeiro, Brasil. Email: prof.wilsonmartinslopes@uol.com.br
} 


\section{ABSTRACT}

This article aims to assist in the important discussion on regionalization with an emphasis on tourism and transport, reflecting on regional development. There was a discussion of the region (regionalization), the core concept of geography in order to clarify the issue and recognize transport and tourism as objects of geographical science in the face of interference in their territory and reflexes in geographic space. Also notable was the important relationship between tourism and the geographical area in which tourism consumes space and its elements so as to make changes in the territory, as the use and installation of public facilities. The importance of this discussion is to contribute to research since the classic regional geography to the geography of the geography of transport and tourism. Research on this subject are important to the government at different levels of planning to implement a regional public policy.

Key words: regionalization; tourism; transport; geography of tourism; regionalization of tourism.

\section{Introdução}

Para o turismo, a questão dos transportes, assim como, a discussão regional, tornaram-se imprescindíveis, seja pela alteração espacial provocada pela prática turística e suas intervenções diretas no território, ou ainda pelos fatores como o mundo globalizado, as políticas públicas, o planejamento, sem falar nas cifras econômicas que cada vez mais despertam interesse por este setor.

A necessidade de estudar a questão regional associada ao turismo e aos transportes é significativa para que se busque a compreensão das diferentes configurações espaciais, em especial das regiões e localidades turísticas, deste modo favorecendo nas políticas públicas e no planejamento.

Temas como região, regionalização, desenvolvimento socioeconômico, logística de transportes, turismo, entre outros, são chamados à discussão da qual os fatores sociais, econômicos, políticos, culturais e ambientais são decisivos na (re) organização das regiões.

Há diferentes formas de se entender a região, como conceituações diversas, além de tantas outras teorias para explicar a sua formação, características, como até mesmo a sua própria noção a luz da "História do Pensamento Geográfico". Essa diversidade é presente na reflexão sobre 
regionalização e o seu entendimento, em especial, quando aplicado aos transportes e o turismo.

Nas discussões epistemológicas sobre região várias correntes que a discutem, apesar de nem sempre haver consenso. Todavia, a discussão conceitual se faz importante uma vez que indiretamente influencia nas políticas públicas, sejam elas em escala municipal, estadual ou federal. Deste modo há a necessidade de se buscar a compreensão do contexto político e os critérios utilizados nas regionalizações (político administrativa e turística) que envolvem os municípios turísticos, além das próprias políticas públicas e 0 comportamento econômico.

Neste contexto, o turismo e os transportes se destacam junto à regionalização e a discussão sobre o possível desenvolvimento propiciado pelo turismo aos municípios e a população. Assim, torna-se também importante 0 entendimento do papel dos transportes em diferentes regiões como possível indutor de desenvolvimento econômico e do turismo, considerando a circulação de pessoas e produtos entre os municípios dessas regiões, possibilitados consequentemente pela infraestrutura de transportes instaladas.

Quando uma região recebe melhoria na infraestrutura de transportes, a mudança econômica em diferentes setores da economia da própria região costuma ser facilmente identificada através do fluxo de comércio e de pessoas, sendo que esta modificação no nível de acessibilidade e circulação colabora não somente na escala intrarregional, mas também interregional. Entretanto, para dimensionar de forma mais precisa as implicações da instalação da infraestrutura, assim como do papel da infraestrutura de transportes já instalada para o desenvolvimento de uma região, é necessário uma avaliação sistemática.

Deste modo, pesquisas são necessárias na perspectiva de avaliar a questão da infraestrutura dos transportes, o turismo, e outras variáveis para a discussão sobre o desenvolvimento regional que envolve um complexo processo de mudanças econômicas, políticas e sociais associadas ao crescimento econômico que atenda as demandas sociais. Também o papel do Estado e seus reais interesses na região e regionalização necessitam ser 
levantados, pois, estes podem ser os mais diferentes, desde favorecer a própria circulação e acesso entre a população da região, ou melhorar a competitividade das empresas existentes e até mesmo atrair novos investimentos para a região.

Justamente provocar a reflexão sobre a temática, assim como futuras pesquisas, sobre região - regionalização junto do turismo e transportes é o objetivo deste artigo. Intencionou-se apresentar de forma ampla alguns importantes conceitos e idéias sobre o tema em questão para favorecer estudos futuros nessa importante área da geografia e do turismo. Portanto, o presente texto apresenta-se inicialmente através de considerações teóricas sobre região e regionalização e posteriormente sobre transportes e turismo.

\section{Aspectos geográficos sobre região e regionalização}

É a partir do espaço geográfico que se torna possível a relação espaço/região na perspectiva que a região faz parte do todo espacial, portanto, a região constitui-se num "subespaço" funcional do todo, como uma escala de análise. Desta forma, a região faz parte de uma totalidade que é alterada pela sociedade e o seu processo histórico, de modo que na medida em que a noção de região muda com o tempo altera-se a interpretação de totalidade e da relação espaço e tempo.

Nessa relação espaço e região, a região apresenta-se praticamente como um recorte no espaço, e por se apresentar como um conceito produzido, ganha diferentes faces, ou possibilidades na perspectiva de regionalização. Enfim, é a partir do conceito de espaço geográfico que se analisa, discute a noção de região e a regionalização.

Entre os geógrafos há muita discussão e consequentemente diferenças no entendimento de região, o que provoca diferentes interpretações e conceitos. Diferenças essas, notadas ou acompanhadas ao longo da história do pensamento geográfico e as suas correntes, desde a geografia clássica até pós-moderna. O que é indiscutível nesta questão é a importância desta 
categoria de análise para a ciência geográfica, assim como para outras áreas, como exemplo, o turismo.

Num sentido de conquistas territoriais, na antiguidade, o termo região esteve presente, assim como também já era utilizado no âmbito do Estado e de discussões políticas. Mas, também o termo região foi como ainda é muito presente no dia a dia da sociedade, ou seja, no senso comum. Isso faz com que o termo esteja tão enraizado na população com significado ou emprego um pouco deturpado se considerado para a ciência geografia.

\begin{abstract}
... a palavra região é de uso fluido e tem dificuldades em se estabelecer como um conceito. Quem já não ouviu falar destas expressões: região em que nasci, região perigosa ou região de fulano e de sicrano, disso ou daquilo? Essa idéia de região que aparece na linguagem corrente indica recortes do espaço que os indivíduos ou grupos sociais elaboram e passam a ser reconhecidos, ou não, socialmente. Esses recortes se multiplicam à medida que a percepção do espaço de cada um se amplia, fazendo-os perceber o homogêneo e o diferente acerca do mundo. (LENCIONI, 1999, p. 16-17).
\end{abstract}

Mas, a região enquanto categoria de análise geográfica, como é assumida neste artigo, favorece na compreensão dos diferentes fenômenos do espaço geográfico, no entanto, esta categoria, a região, passa por mudanças conceituais e metodológicas significativas na perspectiva da história do pensamento geográfico. As próprias mudanças, ou rupturas na perspectiva dos paradigmas geográficos influenciaram a região de modo a explicitar diferentes formas de abordagens.

Merece ênfase que para o entendimento da categoria região, além dos diferentes paradigmas e contextos geográficos e históricos, são presentes variáveis sociais, políticas e econômicas.

Outro aspecto a se refletir, é a questão da regionalização, que é presente em diferentes áreas de administração pública, planejamento, saúde, educação, entre outras, em especial transportes e turismo, objeto deste artigo. Isso porque a logística de transportes, ou a implantação de um sistema de transportes por parte do Estado está intimamente relacionada ao contexto regional, favorecendo ou até mesmo dificultando o desenvolvimento de parte de uma região, ou de alguns municípios. Assim, também há a possibilidade de 
desenvolvimento do turismo regional, que é dependente do sistema de transportes que possibilita a fluidez no território, ou seja, o fluxo turístico.

Mas para regionalizar, isto é, o processo de dividir o espaço, é necessário ter como diretriz um conceito de região, e mais que isso ter critérios.

\begin{abstract}
Regionalizar passa a ser a tarefa de dividir o espaço segundo diferentes critérios que são devidamente explicitados e que variam segundo as intenções explicativas de cada trabalho. As divisões não são definitivas, nem pretendem inscrever a totalidade da diversidade espacial, elas devem simplesmente contribuir para o entendimento de um problema, colaborar em uma dada explicação. (GOMES in CASTRO; GOMES; COSTA, 1995, p. 63)
\end{abstract}

Apenas para ilustrar seguem alguns aspectos problemáticos ou polêmicos da regionalização, ou ainda variáveis que devem ser consideradas a saber: a demarcação que depende dos aspectos que deseja enfatizar; as vantagens e desvantagens de cada maneira de regionalizar; o limite da região em relação ao limite dos estados e do fixado pelo Instituto Brasileiro de Geografia e Estatística - IBGE; a dinâmica socioespacial e a própria dinâmica regional; o desenvolvimento desigual e combinado, entre outros.

Com intuito de apresentar um pouco sobre região na história do pensamento geográfico, aspecto esse essencial para a discussão da temática aqui apresentada, seguem algumas considerações a respeito, mas sem a intenção de analisar com rigor essa categoria na perspectiva epistemológica.

De acordo com Moraes (2002) a geografia se institucionaliza no final do século XIX, sustentada no modelo positivista tendo como expressão duas escolas referenciadas pelos países, Alemanha e França. O conhecimento geográfico estava atrelado à conquista territorial, busca de matérias-primas e 0 despertar de um sentimento nacionalista, logo colocando a geografia e seu conhecimento, como algo, de suma importância para o Estado - Nação.

Neste contexto tem-se a estruturação da geografia ainda no positivismo do século XVIII de Emmanuel Kant, que buscava um conhecimento objetivo. Segundo Lencioni (1999), é Kant que identifica o espaço como objeto da geografia, e também relacionando a região como subdivisão espacial. 
Ao que diz respeito á região, na geografia Tradicional ou Clássica, temse segundo Capel (1985), duas diretrizes que se constituirão enquanto dilemas na geografia, em especial, para a região. O primeiro era "estudo da relação do homem com o meio", enquanto o segundo "o estudo da diferenciação do espaço". O primeiro sustentou o conceito de região natural de Ratzel, já o segundo a região geográfica de La Blache. Destaca-se que os dois estão embasados em concepções naturalistas, porém, no caso da região para La Blache, ou seja, região geográfica há um caráter de historicismo e do elemento humano que diferencia do conceito de região natural.

A idéia de que as condições naturais determinavam 0 comportamento/desenvolvimento social era a ideologia associada ao conceito de região natural. Ou seja, as influências do meio natural sobre o homem.

\footnotetext{
O conceito de região natural nasce, pois, desta idéia de que o ambiente tem certo domínio sobre a orientação do desenvolvimento da sociedade. Surge daí o primeiro debate que tem a região como um dos epicentros, o conhecido debate entre as determinações e as influências do meio natural. (GOMES, in: CASTRO; GOMES; CORREA, 1995, p. 55)
}

Vale mencionar que esta perspectiva ficou conhecida especialmente, pela Alemanha, e recebeu a denominação de determinismo ambiental. Destaca-se nesta linha a integração dos elementos da natureza e sua determinação no comportamento como progresso da sociedade.

\footnotetext{
... as condições naturais especialmente as climáticas ... determinam o comportamento do homem, interferindo na sua capacidade de progredir. Cresceriam aqueles países ou povos que estivessem localizados em áreas meteorológicas mais propícias. (CORREA, 1991, p.9)
}

A região geográfica, de La Blache, difundida especialmente pela escola francesa conhecida como "possibilista", que se opunha ao determinismo destacava a natureza como elemento caracterizador de determinada área (região) enquanto o homem imprimia sua individualidade. Deste modo, a região constituía-se num produto do homem, de sua ação, em uma determinada área. 


\begin{abstract}
Segundo esta perspectiva 'possibilista', as regiões existem como unidades básicas do saber geográfico, não como unidade morfológica e fisicamente pré-constituídas, mas sim como o resultado do trabalho humano em um determinado ambiente. É assim as formas de civilização, a ação humana, os gêneros de vida, que devem ser interrogados para compreendermos uma determinada região. (GOMES, in: CASTRO; GOMES; CORREA, 1995, p. 56)
\end{abstract}

Portanto, o sentido da região para o possibilismo, ou em específico para Vidal de La Blache, apresenta-se como uma paisagem onde estão presentes homem e a natureza que imprimem a peculiaridade de cada região, tendo os limites impressos pelos elementos como clima, solo, vegetação.

Mas, justamente da dimensão dada ao homem à paisagem regional, que por sua vez se estruturou da relação entre o homem e o meio, e que, favoreceu a análise regional, e em particular a formação da geografia regional, que surgem alguns problemas. Ocorre que decorrente da valorização do homem neste contexto surgiu á dualidade homem - meio e, essa só foi resolvida com o surgimento da própria geografia regional, mas também fez emergir outra dualidade: a geografia geral e a regional.

Neste contexto destaca-se Hettner, que segundo Gomes in Castro (1995) seguindo o neokantismo, discute questão das ciências nomotéticas (estudos gerais) e idiográficas (estudos particulares), isso a partir de não concordar com o uso de um único método pelas ciências humanas e naturais. Decorre disto Hettner defende a corologia, ou seja, o estudo da diferenciação de áreas a partir da diversidade tanto dos aspectos humanos quanto os físicos.

Como seguidor de Hettner, destacou-se Hartshorne expressivo para o método regional, e, defensor de região como uma criação intelectual que integra fenômenos diferentes numa área. A região para Hartshorne, segundo Correa (1995, p.15) “... busca a integração entre fenômenos heterogêneos em seções de espaço terrestre. Estes fenômenos ... contribuem para a diferenciação de áreas."

No método regional há um desprendimento ao que se refere a relação homem e natureza, e uma valorização dos fenômenos heterogêneos, assim a região colaborando na interpretação de uma parte do espaço, que seria como uma síntese dos aspectos físicos e humanos. 
Mas a falta de critérios, teorias, modelos, enfim, e seu caráter descritivo foi alvo de críticas para o método regional de modo a surgir a nova geografia que por sua vez defendia técnicas e modelos matemáticos que dariam o caráter científico ausente na geografia, em especial na região para o método regional.

Agora, na nova geografia, a região é enfocada sob técnicas estatísticas, classificações, entretanto, distante do trabalho de campo e de um discurso teórico inovador.

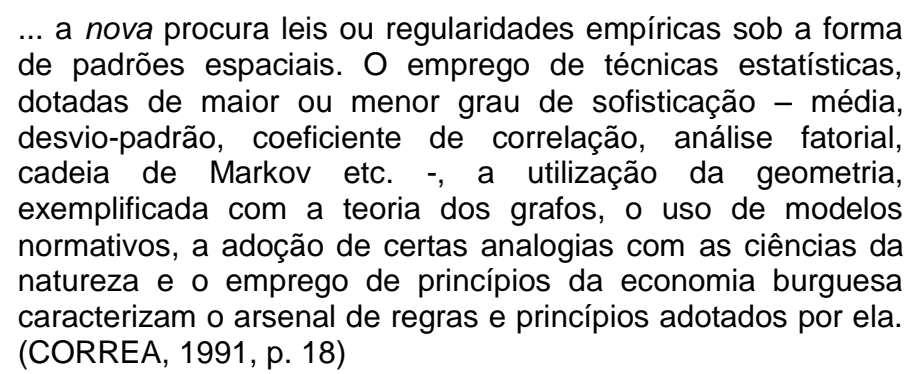

Deste modo, surge uma região isenta da dimensão histórica, mas funcional, na perspectiva de aplicabilidade de teorias, modelos, técnicas e toda uma sistematização a favor da burguesia. Portanto, funcional ao Estado e a burguesia num planejamento regional que vislumbrava eficiência e defesa de interesses e ideologias de uma classe específica.

$\mathrm{Na}$ década de 1970, no contexto da corrente crítica da geografia, dividida em marxista e fenomenológica, há uma preocupação comum para com a geografia, a falta da dimensão social. E, no caso da região, aspectos históricos e culturais passaram a integrar uma nova perspectiva de geografia regional.

No caso da marxista, comumente chamada de "geografia crítica", a questão da região teve uma peculiaridade, ocorre que Marx não trabalhou essa questão. Diante disto, segundo Lencioni (1999b) buscou-se sustentar a região na descrição, mas fazendo parte de um todo histórico, e, não harmônico, haja vista que a intenção era mesmo de apontar as diferenças, desigualdades a partir da discussão de propriedade, classes sociais, produção, consumo, e outros. Portanto, enfatizavam-se as desigualdades espaciais, por sua vez 
sustentadas no processo de acumulação capitalista explícito na divisão sócioespacial do trabalho.

\begin{abstract}
... à divisão territorial do trabalho e ao processo de acumulação capitalista que produz e distingue espacialmente possuidores e despossuídos. Desta forma, a identificação de regiões deve se ter aquilo que é essencial no processo de produção do espaço, isto é, à divisão sócio-espacial do trabalho. (GOMES in: CASTRO; GOMES; CORREA, 1995, p. 65)
\end{abstract}

Neste sentido a regionalização com base nas diferenças espaciais entre possuidores e despossuídos pode ser expandida também para dimensões internacionais além de nacionais, sendo assim uma questão de escala. Seja entre países ou dentro de um próprio país, a regionalização, e em especial, a própria região, é resultado das diferenciações espaciais decorrentes do desenvolvimento desigual e combinado.

\begin{abstract}
A lei do desenvolvimento desigual e combinado traduz-se, assim, no processo de regionalização que diferencia não só países entre si como, em cada um deles, suas partes componentes, originando regiões desigualmente desenvolvidas, mas articuladas. (...) A região pode ser vista como um resultado da lei do desenvolvimento desigual $\mathrm{e}$ combinado, caracterizada pela sua inserção na divisão nacional e internacional do trabalho e pela associação de relações de produção distintas. (CORREA, 1995, p.45)
\end{abstract}

Portanto, a divisão nacional e internacional do trabalho e as relações de produção imprimem ao espaço as diferentes regionalizações que, para a geografia crítica marxista são os elementos da discussão e do entendimento da região.

No caso da outra corrente também crítica, a geografia humanística, para entender a região é colocada a necessidade de vivê-la, contrária ao que é objetivo, quantitativo, valorizou-se a subjetividade, privilegiando o interesse do individual e não de classes, daí destacar-se o conceito de espaço vivido. Conforme Gomes in Castro; Gomes; Correa (1995, p. 214) “... produto real, construído dentro de um quadro de solidariedade territorial”. Assim, a análise espacial passou a receber uma atenção significativa de carga subjetiva, com influência até mesmo da psicologia. 
O que foi apresentado são aspectos gerais sobre região com o intuito de favorecer o entendimento de regionalização a luz da história do pensamento geográfico, entretanto, de acordo com o objetivo de outras diferentes pesquisas sobre essa temática o enfoque e aprofundamento pode ser maior. A seguir destaca-se a questão da logística dos transportes e do turismo na regionalização.

\section{A logística dos transportes e os modais}

No processo de crescimento econômico e de integração do território, o setor de transportes é essencial assim como também para o desenvolvimento econômico de regiões, municípios e até mesmo para prática do turismo. A própria evolução e o desenvolvimento da humanidade estão em grande parte sustentados na também evolução dos transportes.

De acordo com Keedi; Mendonça (2000), o homem evoluiu na medida em que os meios de transporte evoluíram. Há milhões de anos o homem sentiu a necessidade de locomover em busca de alimentos, além de transportar os equipamentos e utensílios que possuíam. Assim, a partir das necessidades básicas desde a busca por alimentos, exploração dos recursos naturais, as trocas, e o próprio comércio e produção industrial, os transportes trilharam uma contínua evolução com fases, ou momentos históricos. Nesta perspectiva, desde as sociedades antigas, os animais eram utilizados como meio de locomoção, mas após a Revolução Industrial, aproximadamente no século XIX, que ocorre a revolução dos transportes com o surgimento das primeiras ferrovias e barcos a vapor. A partir desta fase inicia-se a evolução tecnológica que colaborou com os sucessivos avanços nos transportes favorecendo a mobilidade e circulação.

Segundo Faria (2001) numa perspectiva de evolução dos transportes pode se destacar os seguintes aspectos ou momentos em sua história: Produtos/mercadorias disponíveis em locais distantes; Uso de cestas, plataformas, carroças; Tração animal - processo domesticação de animais; Primeiros veículos sobre roda com tração animal em 3500 a.C.; Romanos 
construíram pontes e estradas pavimentadas; Inicio do transporte aquaviário; Revolução Industrial século XVIII grande impulso com máquina a vapor - trem e barco; Final século XIX indústria automobilística e também o caminhão.

Nota-se a sucessão de fases atreladas á evolução técnica e tecnológica assim como dos diferentes meios, ou modalidades de transportes. O sistema de transportes e seus modais são os responsáveis pelo desenvolvimento econômico-social das diferentes partes do mundo, pois a circulação de pessoas, como também de mercadorias, sustentam principalmente as áreas com grandes concentrações populacionais.

Ao que se refere aos modais de transportes, de acordo com Hara (2005) e Keedi (2004) os transportes possuem cinco tipos de modais, (ferroviário, rodoviário, aéreo, hidroviário, dutoviário), cada um com custos e características operacionais próprias, que os tornam mais adequados para certos tipos de operações e produtos. Todas essas modalidades têm suas vantagens e desvantagens. Algumas são adequadas para um determinado tipo de transportes e outras não. Em sua escolha devem ser considerados aspectos como: custos, características de serviços, rotas possíveis, capacidade de transporte, versatilidade, segurança e rapidez. Vale destacar que essa questão refere-se especialmente ao transporte de cargas.

$\mathrm{Na}$ atualidade merece destaque o papel dos transportes na logística, conforme Ballou (2001, p. 21), entendida como “... o processo de planejamento, implementação e controle do fluxo eficiente e economicamente eficaz de matérias-primas, estoque em processo, produtos acabados e informações relativas desde o ponto de origem até o ponto de consumo, com o propósito de atender às exigências dos clientes". Na logística os transportes destacam-se pela sua função de transporte/deslocamento sendo responsável entre um e dois terços do total dos custos logísticos, segundo Ballou (2001), o que implica obrigatoriamente no preço final dos produtos. Desta forma, a sua importância nos custos logísticos para as empresas é considerável através dos fretes.

Se analisado o âmbito econômico, a questão dos transportes, da circulação sempre esteve presente no mundo, e com o seu desenvolvimento 
houve o favorecimento da distribuição dos homens e das coisas, assim como também ocorreu ás aglomerações humanas.

\begin{abstract}
... os transportes imprimiram marcas indeléveis na paisagem. Eles têm modificado profundamente os aspectos da natureza, e por vezes sobre continentes inteiros. A maior parte das aglomerações humanas são filhas da circulação. Assim, sob todas as suas formas, a circulação dos homens e das mercadorias é um aspecto fundamental da geografia física e humana. Ela depende de uma, ela cria a outra, ela reage sobre ambas. É tão necessária à vida do globo terrestre como a circulação do sangue à vida do organismo humano. (SILVA, 1949, p.243)
\end{abstract}

A ocupação e formação espacial, assim como a circulação dos homens e das mercadorias, neste contexto dos transportes constituem-se objeto de estudos da geografia. As marcas existentes no território vão além dos transportes, configurando o território com "fixos" e os "fluxos", segundo Santos (2004) essenciais às análises geográficas.

Assim, o território é ordenado na perspectiva da estruturação das vias de transportes, sendo que em alguns casos somente com a estruturação das vias de transportes ocorre a ocupação territorial, e, em outros casos ocorre o contrário, ou seja, a implantação de vias de transportes favorece a ocupação. O que é inquestionável é a importância do sistema de transportes para a ocupação e formação espacial, assim como o desenvolvimento econômico. Neste contexto tem-se a dialética, território - circulação, sendo mediada pelos sistemas de transportes.

Não somente os transportes, mas as infraestruturas em geral, condicionam o desenvolvimento regional através de suas atividades econômicas. Inclusive algumas infraestruturas podem colaborar no padrão de vida da população, até mesmo diminuindo a pobreza. No ponto de vista econômico, assim como social, os transportes contribuem para o desenvolvimento regional, permite transpor barreiras físicas, encurtar distâncias, intensificar as trocas comerciais, redução de custos, enfim colaborando na circulação de fluxos, entre outros.

$\mathrm{Na}$ perspectiva regional o importante é que as redes de transportes possibilitem a viabilidade social, econômica e financeira, de forma a favorecer 
um melhor nível da população. Desta maneira, o desenvolvimento do setor de transportes necessitaria integrar os municípios de uma determinada região, assim como também favorecer o contato destes com outras regiões. A mobilidade da população, e também de cargas, são imprescindíveis nesta visão de desenvolvimento regional. Entretanto, vale destacar que o desenvolvimento regional não depende somente do desenvolvimento dos transportes, mas de investimentos em outros setores, assim como a definição de políticas públicas comprometidas não somente com o econômico, mas também o social.

Nota-se que no caso do desenvolvimento regional, e dos seus municípios, os transportes cumprem papel de excelência. Mas também no desenvolvimento do turismo o sistema de transportes é essencial, a ponto de favorecê-lo, ou até mesmo inviabilizá-lo. Pode se identificar essa importância na atenção dedicada por parte dos governos e secretarias do turismo à questão dos transportes, como constatado no próprio site do Ministério do Turismo, no qual uma das categorias internas discutidas sobre o turismo ser "Logística de Transportes", compondo um programa específico para o turismo destacando o sistema de transportes. De acordo com o Ministério do Turismo, Brasil (2010), "O transporte é um componente fundamental da atividade turística, por isso, foi introduzido este programa como um eixo temático específico, em função da importância que apresenta para o desenvolvimento dessa atividade no País".

Para o turismo, os meios de transportes são essenciais. A prática do turismo está totalmente sustentada no setor de transportes, para assegurar o seu desenvolvimento. A discussão inicia-se já pelo próprio turista ao decidir viajar que pensa imediatamente em que meio de transporte utilizar. A questão é complexa, pois na perspectiva do desenvolvimento regional do turismo, a logística de transportes é fundamental na atividade turística, pois é responsável pela circulação, ou seja, o acesso do turista até o local turístico (receptor). 


\section{Aspectos da geografia do turismo}

Neste momento do texto, propõe-se destacar alguns pontos essenciais à reflexão sobre a geografia e os transportes como elementos essenciais na regionalização e desenvolvimento do turismo. Para tanto, parte-se da importante relação entre o turismo e o espaço geográfico na qual o turismo consome o espaço e seus elementos de modo a imprimir mudanças no território como do uso e da instalação de equipamentos públicos, além das diferentes relações que se travam entre turistas e comunidades receptoras.

\footnotetext{
O turismo é uma atividade que se desenvolve por meio dos elementos dos espaços geográficos. Assim sendo, ao utilizar a natureza como atrativo turístico, os equipamentos urbanos como infraestrutura do turismo, os territórios de origens de turistas, as comunidades receptoras com sua população residente e as práticas sociais decorrentes deste encontro, 0 turismo passa a ser objeto do saber geográfico. (CORIOLANO, 1998, p.21)
}

É perceptível a relação da geografia com o turismo, uma vez que é através do espaço geográfico que se dá o desenvolvimento do turismo, decorrente disto a importância da geografia para um melhor entendimento do fenômeno do turismo e suas transformações socioespaciais.

Ao que se refere ao espaço geográfico, segundo Carlos apud Cruz in Cruz (2007, p.4) “... o turismo representa a conquista de uma importante parcela do espaço que se transforma em mercadoria...", ou seja, o turismo conquista uma parte do espaço de forma a transformá-lo para atender as suas necessidades, para tanto se utiliza da infraestrutura já instalada, assim como de novos objetos instalados no território para atender a finalidade turística.

\footnotetext{
Para que o turismo possa acontecer, os territórios vão se ajustando às necessidades trazidas por essa prática social. Novos objetos e ações; objetos antigos e novas ações; novas paisagens, velhas e novas ações: essa é a lógica da organização socioespacial promovida pela prática do turismo. (CRUZ, 2000, p. 19)
}

Nota-se a transformação do turismo que cria e recria formas espaciais das mais diversas, através de um processo de estruturação que chama a 
geografia à discussão desta prática social que envolve objetos e ações, conforme Santos (2004) em sua organização socioespacial.

Neste cenário de transformação socioespacial provocado pelo turismo apresenta-se a geografia do turismo, que, sustenta-se teoricamente no espaço geográfico perpassando outros importantes conceitos da ciência geografia como região, território, paisagem e lugar além de considerar a discussão/definição de turismo e viagem, e seus temas correlatos sustentabilidade, valores culturais, políticas públicas, planejamento, marketing, e transportes, entre outros.

Deste modo, a geografia é essencial nesta discussão ao contribuir com referencial de sustentação teórico-metodológico através dos seus conceitos de e categorias de análise geográficas, que mostram a íntima relação entre geografia e turismo e está explícita nas diferentes alterações ocorridas no espaço geográfico. Também merece ênfase a importância da geografia para o turismo em considerar as necessidades dos lugares às demandas do turismo, pensado desde a estruturação do território (sistemas de transporte, infraestruturas...) até mesmo na dinâmica social.

Mas é na economia, em especial através dos números, que o turismo tem se destacado a ponto de despertar cada vez mais o interesse de inúmeros países e empreendedores neste setor.

\footnotetext{
O Turismo é uma das principais atividades econômicas do planeta, respondendo por 01 (um) em cada 10 (dez) postos de trabalho em todo o mundo. Movimentou cerca de US $\$ 3,5$ trilhões em 2003, ou 10\% do PIB mundial. Em 2002, 715 milhões de pessoas viajaram de um país para outro, movimentando US $\$ 474$ bilhões. (LIMA; ZOTES, 2008, p. 2-3)
}

Na mesma perspectiva, Trigueiro (2001), afirma que mais da metade dos países que compõem a Organização das Nações Unidas - ONU têm o turismo como maior ou segundo maior negócio econômico. O mesmo autor ainda destaca que em países como, Grécia, Espanha e Áustria, o turismo representa mais de 20 \% de suas exportações, e, no caso do Caribe, o turismo gera mais de $70 \%$ de empregos e renda dos países. 
Através desses índices, assim como outros que apresentam somente 0 lado econômico positivo do turismo, surgem cada vez mais novos países interessados em desenvolver a prática turística, assim como se destacam novas modalidades de turismo no âmbito econômico, como o turismo: de negócios, eventos, saúde, ecológico, artístico - cultural, histórico, entre outros. Mas atualmente além dos benefícios econômicos, expressos por diferentes índices, outros aspectos têm sido discutidos como os custos, ou seja, o impacto negativo desta atividade para as áreas receptoras e até mesmo emissoras.

\footnotetext{
Hoje o mundo inteiro começa a falar dos custos e dos benefícios do turismo para a economia, o meio ambiente e a sociedade, quando antigamente tratavam apenas das vantagens e das questões econômicas. (KRIPPENDORF, 2001, p.96)
}

Os diferentes impactos negativos do turismo vão desde o aumento do custo de vida, especulação imobiliária, choque cultural, degradação ambiental, entre outros, que passaram a ser amplamente discutidos e considerados no planejamento atual.

Mas mesmo diante dos impactos ainda é comum o turismo ser apresentado como a grande opção para o desenvolvimento econômico, em especial, dos municípios que estão estagnados economicamente. Costuma-se destacar até mesmo o turismo como elemento capaz de solucionar os diferentes problemas de ordem socioeconômica. No entanto, essas colocações são complexas, faz-se necessário também refletir sobre qual o tipo de desenvolvimento que o turismo pode proporcionar para uma região, assim como aos seus municípios, além de quem o turismo realmente pode beneficiar.

Ao que se refere a essa polêmica questão e, de modo mais específico, sobre o desenvolvimento socioeconômico provocado pelo turismo enquanto gerador de empregos, renda e também qualidade de vida, existem inúmeros autores que defendem essa posição, dentre eles: Arrillaga (1976), Beni (2001), Sessa (1983), Yázigi (1999). Mas também há outros autores como Krippendorf (1989) e Urry (2000), que colocam o turismo como atividade insustentável, além de depredadora dos aspectos ambientais, culturais e outros. 
No Brasil a questão do desenvolvimento socioeconômico atrelado ao turismo, tem sido tratada pelo Ministério do Turismo, conforme Brasil (2004), no ano de 2003 foi criado o Ministério do Turismo com a responsabilidade de divulgar o turismo como elemento essencial para $\circ$ desenvolvimento socioeconômico do país. O Ministério do Turismo passa a defender a idéia de que o turismo quando planejado tem a capacidade de desenvolvimento econômico, como também de gerar benefícios sociais para a população de um município. Decorrente disto, o Ministério coloca aos municípios a responsabilidade para gerenciar, implantar e desenvolver as questões referentes ao turismo, sendo que nesta política já é observada uma tendência a regionalização do turismo.

No ano de 2004, segundo a EMBRATUR (2007) inicia-se o Programa de Regionalização do Turismo tendo como objetivo desenvolver o turismo de forma regionalizada no Brasil e colaborar com a ampliação e estruturação da atividade turística na perspectiva regional e considerando a sustentabilidade.

Diante do exposto até o momento vale destacar que para que o turismo seja também importante na perspectiva de desenvolvimento socioeconômico, é necessário um sistema de transportes que o favoreça. Sabe-se que as interferências do turismo além de espaciais são territoriais, pois o turismo se manifesta de diferentes formas no território estando suas manifestações sob a intenção da iniciativa privada e do próprio Estado. Neste sentido que o sistema de transportes é imprescindível para o seu acontecimento, e na perspectiva de um turismo como opção econômica que de fato colabore com os municípios e a população local, essa infraestrutura deve ser considerada.

Conforme Cruz $(2003 ; 2007)$ o turismo necessita de infraestrutura para favorecer a fluidez no território, pois sua prática é totalmente relacionada ao deslocamento, decorrente disto a utilização de infraestrutura, em especial, a de transportes já instalada e a adequação destas, assim como a instalação de novas, torna-se necessário. De acordo com Cruz (2007, p. 12) "A criação de um novo sistema de objetos é, portanto, acompanhada pela adequação de objetos preexistentes aos novos usos requeridos pelo turismo...". Essas alterações, por sua vez, provocam as transformações socioespaciais tendo 
neste caso, a acessibilidade dos turistas como causa para essas mudanças na infraestrutura dos transportes e consequentemente espacial.

O próprio Ministério do Turismo divulga em seu site, a Logística de Transportes como um dos pilares no seu Plano Nacional de Turismo - PNT, que por sua vez, determina a Regionalização do Turismo, como uma diretriz para os municípios e regiões se desenvolverem. Portanto, percebe-se a relação entre a questão da região - regionalização, os transportes e o turismo, na perspectiva do desenvolvimento socioeconômico e a importância de pesquisas nesta área.

Para complementar essas questões de regionalização do turismo e os transportes, acredita-se que deva entendê-lo como uma possibilidade para o desenvolvimento territorial e não como elemento capaz de solucionar os problemas socioeconômicos e regionais.

\begin{abstract}
O turismo deve ser visto, portanto, como uma opção na busca do desenvolvimento territorial, e não como uma panacéia para resolver o problema dos desníveis regionais, ou da assimetria intra-regional. Melhor dizendo, o incremento do turismo por si só não é capaz de superar as iniqüidades dos modelos de desenvolvimento econômico que provocam o aprofundamento das desigualdades entre as regiões, ou que privilegiam sobremodo uma minoria da população que habita uma determinada região. (SILVEIRA in SOUZA, 2002, p.43-44)
\end{abstract}

Outro aspecto relevante nesta perspectiva é o planejamento, que deve ser realizado por profissionais de formação interdisciplinar e que privilegie os interesses locais, isto é, não restrito (centralizado) a classe empresarial envolvida diretamente com o turismo, mas também acessível à população nativa - local - é imprescindível. O desafio do planejamento está no fato de conciliar interesses diferentes, ou seja, dos turistas que vão consumir o lugar visitado, e dos moradores deste lugar.

O planejamento do turismo é, em princípio, complicado porque tem de conciliar os interesses de uma população que busca o prazer num local, onde outras pessoas vivem e trabalham. Satisfazer a ambas não é tarefa fácil. Neste embate há conflitos freqüentes e inevitáveis, eivados de sentimentos xenofóbicos pelas comunidades anfitriãs. (RODRIGUES, Adyr B. in RODRIGUES, Adyr B., 2001, p. 25) 
A questão do planejamento, também envolve profunda discussão dos complexos conceitos de desenvolvimento, sustentabilidade e cultura. Neste sentido, há necessidade de conhecer os reais interesses e possibilidades da população local na "criação de objetos turísticos", ou melhor, na implantação do turismo numa localidade que até então não estava inserida neste contexto, assim como nas regionalizações.

Diante das inúmeras questões apresentadas que envolvem a regionalização o turismo e os transportes, surgem questões como: Quais os critérios utilizados para a regionalização turística? Qual o papel, do Estado e do Município, enfim, das políticas públicas no desenvolvimento do turismo regional? A regionalização turística contribui para desenvolvimento econômico e social dos municípios turísticos? A infraestrutura de transportes instalada colabora no desenvolvimento turístico? Os modais de transportes mais comuns, rodoviários e ferroviários têm papel expressivo na exploração socioeconômica do turismo regional?

Responder essas questões regionais, assim como outras mais amplas na perspectiva do turismo em âmbito nacional é tarefa difícil, pois muitas teorias ainda estão sendo elaboradas e aplicadas às diferentes realidades turísticas. Também é necessário revisitar conceitos geográficos e propostas metodológicas de diferentes autores para esta análise, além de discutir e, repensar a função do Estado e suas políticas públicas, assim como, o papel do poder em suas diferentes instâncias federal, estadual e municipal.

\section{Considerações finais}

Diante do exposto, esse artigo se propôs a colaborar na importante discussão sobre regionalização avaliando o sistema de transportes, como elemento indutor da economia regional, assim como essencial a prática do turismo. Merece ênfase que as pesquisas sobre esta temática são importantes ao poder público nos diferentes níveis para implementar políticas públicas, sejam estas voltadas ao turismo, específicas aos transportes, ou ainda, para o desenvolvimento regional. Através dos resultados de pesquisas com essa 
temática é possível ter o conhecimento das diferentes situações (regiões pesquisadas) de modo que seus resultados ao serem disponibilizados ao poder público poderão orientar seus trabalhos e investimentos.

A sua importância está também no campo científico, na medida em que contribui para pesquisas em áreas significativas da ciência geográfica, desde a clássica geografia regional até a geografia dos transportes e geografia do turismo. Portanto, realizou-se uma discussão sobre região (regionalização), conceito cerne da geografia de modo a explicitar e reconhecer o tema transportes e turismo, como objetos da ciência geográfica, diante de suas interferências no território e reflexos no espaço geográfico.

Especificamente sobre região identificou-se a sua necessidade $\mathrm{e}$ complexidade para os estudos de regionalização, pois a região é uma escala de análise importante na mediação mundo-lugar. Neste sentido as próprias especificidades e singularidades apenas podem ser identificadas em análises comprometidas não apenas com os fatores macroeconômicos, mas também numa escala menor, microeconômica e que considere subjetividades como $o$ fator cultural.

Também a geografia, por privilegiar-se do trabalho com diferentes escalas tem a possibilidade de efetivar estudos regionais significativos, como do turismo e dos transportes. Nesta perspectiva o estudo regional é importante para se conhecer o movimento do capital no espaço, assim como as transformações territoriais provocadas pelo turismo. Assim, escalas geográficas e sua tramitação em diferentes dimensões, como também os fatores que implicam em alterações regionais, podem revelar realidades ou conhecimentos antes não vistos e que, necessitam ser identificados, analisados e considerados no planejamento.

Outro ponto significativo refere-se ao planejamento, elemento essencial a regionalização do turismo. Notou-se que quando o planejamento objetiva 0 desenvolvimento regional, as aplicações de recursos financeiros não são suficientes para suprimir possíveis desigualdades, pois a problemática regional envolve também o Estado, Municípios e Empresas que muitas vezes não compactuam os mesmos interesses. 
Ainda em relação ao planejamento, faz-se também necessário identificar, nas diferentes regiões turísticas estabelecidas, os seus potenciais turísticos como aspectos históricos, naturais e culturais, pois a região demonstra potencial a ser trabalhado através de planejamento turístico que pesquise questões do seu espaço geográfico e todas as suas variáveis, envolvendo profissionais de diferentes áreas, em especial, geografia e turismo. Neste mesmo sentido, as modalidades de turismo, necessitam ter relação direta com os setores econômicos como o comércio e a indústria dos municípios da região envolvendo iniciativa privada e pública para realmente gerar desenvolvimento socioeconômico em toda a região.

Enfim, sobre o turismo no Brasil, apesar do constante crescimento de sua prática, este setor da economia ainda é uma nova fonte de exploração e merece muita atenção. Isso principalmente se comparado a outros países, como os europeus, onde o turismo é bem estruturado e constitui-se num importante gerador de rendas. O retorno da exploração turística pode refletir positivamente às regiões e aos seus municípios, conforme destacou o Ministério do Turismo de modo que estes podem se beneficiar desta atividade econômica, entretanto, muitos fatores além dos expostos neste artigo devem ser considerados junto de seu planejamento.

\section{Referências bibliográficas}

ARRILLAGA, J. I. Introdução ao turismo. Rio de Janeiro: José Olympio, 1976.

BALLOU, Ronald H. Gerenciamento da cadeia de suprimentos: planejamento, organização e logística empresarial. Porto Alegre: Bookman, 2001.

BENI, M. Globalização do turismo - Importância econômica e social: a realidade brasileira. São Paulo: Aleph, 2001.

BRASIL. Ministério do Turismo. Programa de regionalização do turismo: Diretrizes Políticas. 2004. Disponível em: <http://www.turismo.gov.br>. Acessado em: 09 de janeiro de 2010. 
BRASIL. Ministério do Turismo. Segmentação do turismo - marcos conceituais. 2004. Disponível em: <http://www.turismo.gov.br>. Acessado em: 11 de janeiro de 2010.

BRASIL. Agência Nacional de Transportes Terrestres (ANTT). Ministério dos Transportes. Disponível em: <http://www.antt.gov.br>. Acesso em: 07 de janeiro de 2010.

CAPEL, Horácio. Filosofia y ciência em La geografia contemporânea. Barcelona: Barcanova, 1985

CARLOS, Ana Fani A. O lugar no/do Mundo. São Paulo: Hucitec, 1996 apud CRUZ, R. C. A. O turismo e suas ambigüidades. In: CRUZ, R. C. A. Geografia do Turismo: de lugares a pseudo-lugares. São Paulo: Roca, 2007.

CORIOLANO, Luzia Neide M. T. Do local ao global: o turismo litorâneo cearense. Campinas: Papirus, 1998.

CORRÊA, Roberto Lobato. O espaço urbano. São Paulo: Ática, 1995.

CORREA, Roberto Lobato. Região e organização espacial. São Paulo: Ática, 1991.

CRUZ, R. C. A. Geografia do Turismo: de lugares a pseudo-lugares. São Paulo: Roca, 2007.

CRUZ, R. C. A. Introdução a Geografia do Turismo. Rio de Janeiro: Roca, 2003.

CRUZ, R. C. A. Política de Turismo e Território. São Paulo: Contexto, 2000.

EMBRATUR. Programa de regionalização do turismo, roteiros do Brasil. 2007.

Disponível

em: http://www.turismo.gov.br/portalmtur/opencms/regionalizacao/modulos/docume ntos/arquivos/download_documentos.html. Acessado em: 07 de janeiro de 2010.

FARIA, Sérgio F. S. Fragmentos da História dos Transportes. São Paulo: Aduaneiras, 2001.

GOMES, Paulo César da Costa. O conceito de região e sua discussão. In: CASTRO, Iná Elias de; GOMES, Paulo César da Costa; CORREA, Roberto Lobato. Geografia: conceitos e temas. Rio de Janeiro, Bertrand Brasil, 1995.

HARA, Celso Minoru. Logística: armazenagem, distribuição e trade marketing. Campinas: Alínea, 2005.

KEEDI, Samir; MENDONÇA, Paulo C.C. Transportes e Seguros no Comércio Exterior. 2a. ed - São Paulo: Aduaneiras, 2000.

KEEDI, Samir. Logística de transporte internacional: veículo prático de competitividade. São Paulo: Aduaneiras, 2004.

KRIPPENDORF, J. Sociologia do Turismo: para uma compreensão do lazer e das viagens. Rio de Janeiro: Civilização Brasileira, 1989. 
LENCIONI, Sandra. Região e Geografia. São Paulo: Edusp, 1999

LENCIONI, Sandra. Região e Geografia: A noção de região no pensamento geográfico. In: CARLOS, Ana Fani Alessandri (org.). Novos caminhos da geografia. São Paulo: Contexto, 1999 b.

LIMA, Ana Maria; ZOTES, Luis Pérez. O Balanço Social como instrumento de monitoramento da atividade turística no Brasil. 2008. In: VII SIMPOSIO DE EXCELÊNCIA EM GESTÃO E TECNOLOGIA. Disponível em: < http://www.aedb.br/seget/artigos06/893 Artigo\%20SEGET.pdf>.

MORAES, Antonio Carlos Robert. A gênese da geografia moderna. São Paulo: Hucitec: Annablume, 2002.

NATAL, Jorge Alves. Transportes, território e desenvolvimento econômico: uma contribuição à crítica da formação social brasileira. Rio de Janeiro: Papel Virtual, 2003.

RODRIGUES, Adyr B. Turismo e geografia: reflexões teóricas e enfoques regionais. 3를 edição. São Paulo: Hucitec, 2001.

RODRIGUES, Adyr B. Desafios para os estudiosos do turismo. In: RODRIGUES, Adyr B. (org.). Turismo e Geografia: reflexões teóricas e enfoques regionais. São Paulo: Hucitec, 2001.

SANTOS, Milton. A natureza do espaço: técnica e tempo, razão e emoção. São Paulo: Edusp, 2004.

SESSA, Alberto. Turismo e política de desenvolvimento. Porto Alegre: Uniontur, 1983.

SILVA, Moacir. M. F. Geografia dos transportes no Brasil. Rio de Janeiro: IBGE, 1949.

SILVEIRA, M. A. T. As políticas públicas e a nova configuração territorial do turismo no Brasil. In: SOUZA, M. J. (org.) Políticas públicas e o lugar do turismo. Brasília: UnB; Departamento de Geografia; MMA, p. 39-51, 2002.

TRIGUEIRO, Carlos Meira. Marketing \& turismo: como administrar 0 marketing turístico para uma localidade. Rio de Janeiro: Qualitymarket, 2001

URRY, J. The tourism gaze. London: Sage, 2000.

YÁZIGI; CARLOS; CRUZ, (orgs) Turismo: espaço, paisagem e cultura. São Paulo: Hucitec, 1999.

YÁZIGI, E. Turismo: uma esperança condicional. São Paulo: Global, 1999. 